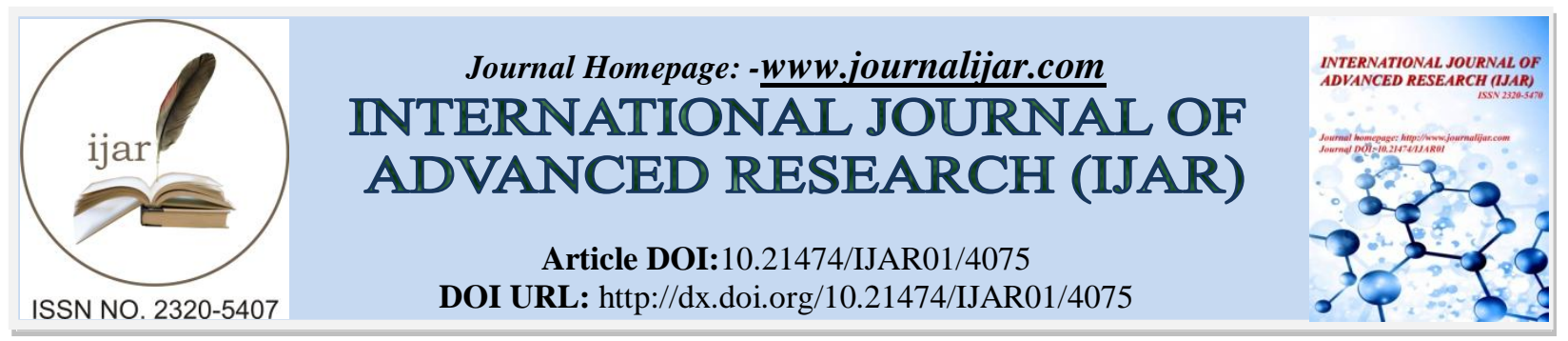

RESEARCH ARTICLE

\title{
NURSES PERCEPTION ON THE USE OF COMPLEMENTARY AND ALTERNATIVE MEDICAL TREATMENT IN CLINICAL SETTINGS; THE CASE OF NURSES AT THE BAMENDA REGIONA HOSPITAL
}

\author{
Nancy Bongkiynuy ${ }^{1,4}$, "Samuel Nambile Cumber ${ }^{2,4}$, Shalom Jaila ${ }^{1,4}$, Rosaline Yumumkah Kanjo Cumber, \\ and Emmanuel N. Tufon'. \\ 1. St Louis University Institute of health and Biomedical Science Bamenda, Cameroon. \\ 2. Discipline of Public Health Medicine, Department of Nursing \& Public Health, College of Health Sciences/ \\ 3. Department of Political Science, University of KwaZulu-Natal, Durban South Africa. \\ 4. Under Privileged Children and Women Assistance (UPCAWA-SWEDEN), Buea, Cameroon.
}

\section{Manuscript Info}

[.........................

Manuscript History

Received: 01 March 2017

Final Accepted: 06 April 2017

Published: May 2017

Key words:-

Medical Treatment; Clinical; Nurses;

Hospital; Cameroon

\section{Abstract}

The use of Complementary and Alternative Medicine (CAM) has been widely documented but not in Cameroon. The aim of this study was to find out the various CAMs known by nurses, the proportion of nurses who recommend CAM to patients and nurses' perception on CAM use in clinical settings. Was a descriptive cross sectional hospital based study which included 45 nurses who had worked for at least a year. A structured questionnaire was used for data collection. The study had female $(66.7 \%)$ and had averagely worked for 1-4years. The results revealed that $(51.4 \%)$ used traditional medicine, followed by $(27.0 \%)$ who used traditional medicine + spiritual healing, while $(8.1 \%)$ used message. Also (57.8\%) had recommended CAM to their patients in disease conditions like typhoid (42\%), Pain management (19.2\%) and incurable diseases $(19.2 \%)$. Participants $(82.2 \%)$ stated that they had frequently encounter patients in the clinical setting who enquired about CAM, though some nurses had reduced attention (16.2). Nurses $(66 \%)$ stated that they will accept CAM use in clinical setting. Nurses (88.9\%) had a positive perception about CAM use in clinical setting. Majority of nurses know types being traditional medicine and spiritual healing.

Copy Right, IJAR, 2017,. All rights reserved.

\section{Background:-}

The use of CAM has evidently expanded since 1990 globally for example in USA with about $38 \%$, over a million users of CAM in Europe, Australia is greater than $70 \%^{[1,2,3]}$. About $70 \%$ of Canadians and $80 \%$ of Germans have taken a natural remedy at some point in their life. CAMs are commonly used in treatment of degenerative and chronic diseases ${ }^{[4]}$.

Over the past 30 years, public interest in the use of CAM approaches, and products has risen steadily in the United States. 4 in 10 Americans used alternative therapies in 1997, a 50 percent increase from 1990. Included in the list of alternative therapies were relaxation techniques, massage, commercial weight-loss programs, lifestyle diets, herbal medicine, self-help groups, hypnosis, and folk ${ }^{[3]}$. 
According to the National Centre for Complementary and Alternative Medicine ${ }^{[5],}$ alternative therapies are grouped into broad categories: alternative medical systems, mind-body interventions, biologically based therapies, manipulative and body-based methods, and energy therapy.

The American Hospital Association in 1998 began collecting in its annual survey information about hospitals that offer CAM services and found that only 6 percent of hospitals reported that they offered such CAM services. By 2001, the number of hospitals offering CAM therapies had more than doubled to 15 percent "indicating a steadily growing interest by hospitals to enter into this arena" ${ }^{\text {,[5]. }}$

In Africa, traditional medicine plays an important role in primary health care due to its accessibility and affordability. In Ghana, Mali, Nigeria and Zambia, the initial treatment for $60 \%$ of children suffering from malaria is with the use of healing plants administered at home ${ }^{[3]}$. WHO reports that $80 \%$ of the African population resorts to traditional medicines and that in several African countries, traditional midwives attend to most births ${ }^{[2]}$.

In Cameroon there is active development in Traditional medicine most especially in the West and North West regions of the country where there is an amalgamation of traditional practitioners to create strong regional associations and organs of operation ${ }^{[3]}$.

The use of CAM has evidently expanded since 1990 globally for example in USA with about 38\%, over a million users of CAM in Europe, Australia is greater than $70 \%[1,2,3]$.

Despite the high rates of utilization of CAM recorded above, little has been done to incorporate this area into nursing practice and education in Cameroon ${ }^{[6,7] \text {. }}$

Nurses cannot advocate for CAM, or understand their patient's use of such treatments, unless they themselves are familiar with both the risks and benefits of these practices in a nursing environment ${ }^{[6,7] \text {. }}$

This study is therefore aimed at finding out nurses' perception of CAM use in clinical settings; the case of Bamenda Regional Hospital NW of Cameroon.

\section{Materials and Methods:-}

A descriptive cross-sectional survey was conducted during the raining season from the $4^{\text {th }}$ of May to the $5^{\text {th }}$ of June 2016 involving nurses who had worked for at least a year at the Bamenda Regional Hospital in the North West Region of Cameroon. Bamenda is an urban city and also the capital city of the North West Region. The inhabitants are mostly civil servant, traders and few farmers. The hospital is located precisely at hospital round-about after the $3^{\text {rd }}$ District Police Station. It acts as a referral hospital in the North West Region. The hospital is being chosen because it has a greater proportion of nurses in the whole region. Bamenda has a population of about 500,000 people. The study population was made up of all nurses working at the Bamenda Regional Hospital.

This study used a descriptive cross sectional design which was hospital based. It was used because respondents were to describe their perception on CAM. There were some inclusion criteria which were taken into consideration for this study, they are; all nurses working at the Bamenda regional hospital; nurses with work experience of at least one year; those who voluntarily signed and filled the questionnaires. Also a few exclusion criteria were considered such as; those who refused to sign and filled the questionnaires; nurses with work experience less than a year.

The participants for this study were selected using simple random sampling approach

A sample of 73 respondents was recruited for this study. Calculation for the sample size can be seen below.

In a study carried out by Chu et al 2006, found out that a P value (0.05) was used.

$\mathrm{CI}=95 \%=1.96$ from $\mathrm{T}$ table.

Emax $=5 \%=0.05$

Prevalence $=0.05$

$\mathrm{n}=\left(\frac{z}{\operatorname{Emax}}\right)^{2} P((1-p))$

Where CI=Confidence level

$\mathrm{n}=\left(\frac{1.96}{0.05}\right)^{2}(0.05)((1-0.05))$

Emax=Maximum Error

$\mathrm{P}=$ Prevalence 
$\mathrm{n}=(1536.64)(0.0475)$

$\mathrm{n}=73$

Data collection was made easy because of the use of the following measuring instruments /tools

- The main instrument for data collection was a structured questionnaire with open and closed ended questions. The questionnaire was self-administered and was divided into two sections such as;

- Section A: Demographic data

- Section B: Nurses perception on CAM

This data collection tool was used for the following reasons;

- Responses was obtained from a wide range of subjects

- Questions were clarified if misunderstood

Data collection process took a month. Data was collected using questionnaires which were administered to participants by the researcher without any assistance. The questionnaire guides consisted of structured and nondisguised questions the questions were closed and open ended. There was a consent form addressed to each respondent informing them about the research and that the responses were to be used purely for research purpose and names were not to be included in the work ensuring confidentiality. To get knowledge on nurses' perception on CAM this question was asked; what is your overall perception on CAM? And the responses were Positive, Negative and Neutral. To know the proportion of nurses willing to accept CAM use in clinical setting this question was posed; would you accept the use of CAM in clinical settings? And the responses were Yes and No. To know the proportion of nurses who have been in contact with patients who use CAM this question was asked; in your nursing practice, have you ever encountered a patient(s) who has enquired about alternative therapy/therapies? And the responses were Yes and No.

These questionnaires were administered and respondents were asked to fill it at their convenience. Each questionnaire was filled for about 10 -15 minutes and all information collected was kept secured. At the end I thanked the respondent for participating.

Data was coded manually and entered into excel and downloaded to SPSS version 20 for analysis and was presented using tables and chart.

A clearance form was obtained from the Head of Department of nursing after submission and approval of the research proposal by the supervisor, which permitted the researcher to carry out the research in the clinical area. There was equally a permission from the medical director of the study area to carry out this work in the hospital. Authorization was obtained from the Regional Delegation of Bamenda.

Some limitations for this study are;

* Many nurses refused to participate in the study due to having been asked recently to participate in other research studies.

* Time was also lost waiting for permission to conduct the study in the study area.

Some strength of the paper;

* This study will contribute to the understanding of CAM by nurses and their uses in clinical setting for patient's care

* The quality of care provided to patients will improve since CAM encompasses holistic care.

* It is well studied and documented that CAM use is occurring ${ }^{[3] . ~ I t ~ i s ~ a l s o ~ k n o w n ~ t h a t ~ a b o u t ~} 73 \%$ of patients,

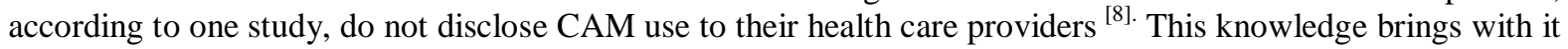
concerns about safety. Drug interactions could occur. Nurses can uncover information that otherwise might be missed if they specifically ask about CAM.

* This study will confirm and strengthen the proposal that nurses and other health care providers ask about CAM use in assessments and histories which will increase safety for both patients and providers. 


\section{Results:-}

Demographic profile

\begin{tabular}{|l|l|l|}
\hline VARIABLES & NUMBER & PERCENT (\%) \\
\hline SEX & & \\
Male & 15 & 33.3 \\
Female & $\mathbf{3 0}$ & $\mathbf{6 6 . 7}$ \\
\hline YEARS IN SERVICE & $\mathbf{2 6}$ & \\
1-4years & 16 & $\mathbf{5 7 . 8}$ \\
5-8years & 3 & 35.6 \\
9and above & & 6.7 \\
\hline HIGHEST QUALIFICATION & $\mathbf{2 2}$ & \\
Degree Nurse & 14 & $\mathbf{4 8 . 9}$ \\
SRN & 7 & 31.1 \\
HND/HPD & 2 & 15.6 \\
Nursing Assistant & $\mathbf{4 5}$ & 4.4 \\
\hline TOTAL & $\mathbf{1 0 0}$ \\
\hline
\end{tabular}

Table 1:-Distribution of Respondents According to Demography Data

This study included 45 respondents. The majority of the participants were females (66.7\%), Most of the participants had been working for 1to 4years $(57.8 \%)$ and most had a degree as the highest level of education $(48.9 \%)$.

Proportion who have idea on CAM and types known

\begin{tabular}{|l|l|l|}
\hline VARIABLES & NUMBER & PERCENT (\%) \\
\hline HAVE AN IDEA ON CAM & & $\mathbf{8 2 . 2}$ \\
Yes & $\mathbf{3 7}$ & 17.8 \\
No & 8 & \\
\hline TYPES OF CAM KNOWN & $\mathbf{1 9}$ & $\mathbf{5 1 . 4}$ \\
Traditional medicine & $\mathbf{1 0}$ & $\mathbf{2 7 . 0}$ \\
Traditional medicine and Spiritual healing & 2 & 5.4 \\
Spiritual healing & 2 & 5.4 \\
Talk therapy & 3 & 8.1 \\
Massage & 1 & 2.7 \\
Music therapy & $\mathbf{4 5}$ & $\mathbf{1 0 0}$ \\
\hline TOTAL & $\mathbf{2 h}$ & \\
\hline
\end{tabular}

Table 2:-Distribution of Respondents according to those who have an Idea on CAM and the Types Known

The results on idea on CAM and types known showed that, (82.2\%) of nurses had an idea on CAM with traditional medicine $(51.4 \%)$ and traditional medicine +spiritual healing (27.0\%) being the most common types of CAM that they know.

Proportion who recommended CAM and types of disease condition
\begin{tabular}{|l|l|l|}
\hline VARIABLES & NUMBER & PERCENT (\%) \\
\hline HAVE RECOMMENDED CAM & & \\
Yes & $\mathbf{2 6}$ & $\mathbf{5 7 . 8}$ \\
No & 12 & 26.7 \\
Not sure & 7 & 15.6 \\
\hline TYPES OF DISEASE CONDITIONS & & \\
Typhoid & $\mathbf{1 1}$ & $\mathbf{4 2 . 3}$ \\
Pain management & 5 & 19.2 \\
Incurable diseases & 5 & 19.2 \\
Malaria & 4 & 15.4 \\
STIs & 1 & 3.9 \\
\hline TOTAL & $\mathbf{4 5}$ & $\mathbf{1 0 0}$ \\
\hline
\end{tabular}


Table 3:- Distribution of Respondents according to those who have Recommended CAM to Patients and the Type of Disease Conditions

From the results, $(57.8 \%)$ of nurses have recommended CAM to their patients in disease conditions like typhoid $(42.3 \%)$, pain management and incurable diseases (19.2\%)

Proportion of those who have encountered patients who use CAM and frequency

\begin{tabular}{|l|l|l|}
\hline VARIABLES & NUMBER & PERCENT (\%) \\
\hline Have Encountered Patients Who Use CAM & & \\
\hline Yes & $\mathbf{3 7}$ & $\mathbf{8 2 . 2}$ \\
\hline No & 8 & 17.8 \\
\hline FREQUENCY & & \\
\hline Frequent & $\mathbf{2 4}$ & $\mathbf{6 4 . 9}$ \\
\hline Seldom & 13 & 35.1 \\
\hline Reaction Towards Patients Who Have Used CAM & & \\
\hline Treat them like any other patient & $\mathbf{3 7}$ & $\mathbf{8 3 . 8}$ \\
\hline Reduced attention & 6 & 16.2 \\
\hline No response & 2 & 4.4 \\
\hline TOTAL & $\mathbf{4 5}$ & $\mathbf{1 0 0}$ \\
\hline
\end{tabular}

Table 4:-Distribution of Respondents according to those who have Encountered Patients who use CAM, Frequency and their Reactions towards them

The results showed that nurses had encountered patients (82.2\%) who used CAM frequently (64.9\%) and they treated them like any other patient $(83.8 \%)$.

\section{Proportion who will accept CAM use in clinical setting}

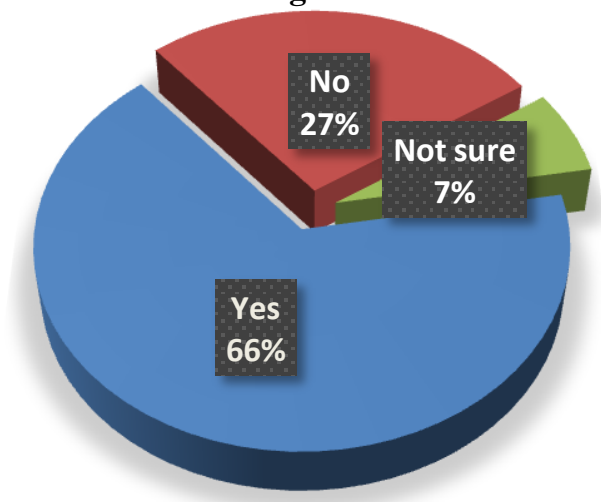

Figure 1:-Represent proportions of nurses who will accept CAM use in clinical setting.

The results showed that (66\%) of nurses will accept the use of CAM in clinical setting while (27\%) will not accept CAM use and (7\%) were not sure of whether to accept or not. 


\section{Perception on CAM}

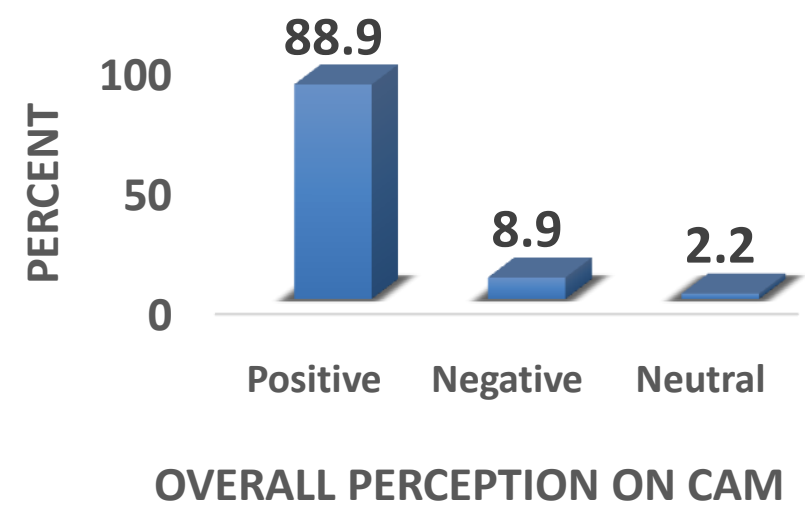

Figure 2:-Represents nurses perception on CAM

The results showed that, $(88.9 \%)$ of nurses had a positive perception on CAM use while $(8.9 \%)$ of nurses had a negative perception on CAM use and only a very few (2.2\%) who had a neutral feeling.

\section{Discussion:-}

There has historically been conflict between conventional medicine and complementary and alternative medicine [6,7]. Despite this conflict, the use, effectiveness, and acceptance of CAM continue to grow ${ }^{[6,7] \text {. }}$

The result of this study (table 4.1) shows a greater proportion of the participants to be female $(66.7 \%)$. This result is in line with the $\left(61.7 \%\right.$ ) female participants in a study by Emmett and also $66 \%$ reported by Sawalha ${ }^{[9,10] .}$ This shows that nursing is largely dominated by females. This reiterates the notion that nursing is a caring profession affiliated with women ${ }^{[11]}$.

The result of this study (table 4.2) show that (82.2\%) of the participants had knowledge on CAM and types known included traditional medicine $(51.4 \%)$, spiritual healing and traditional medicine $(27.0 \%)$. This result, is in line with the study by Green and colleagues where herbal therapy (64.7\%) prayer/spiritual healing (48.4\%) were common CAM methods used and similar to WHO findings with $80 \%$ traditional medicine usage by Africans and the (48.1\%) traditional medicine, $(42.7 \%)$ spiritual healing by $\operatorname{Singh}^{[2,6,7,12]}$. This may be due to the fact that traditional medicine is part of our cultural identity.

This result of high level use of prayer is not surprising, as it is interlinked with spirituality which is deeply rooted in nursing care. Prayer and spirituality are practiced regularly in most hospitals. Some of which have a chapel as well as a resident Chaplain. Both nurses and patients are free to consult the Chaplain or spend quiet time in the chapel. However this study is not in line with studies by Bjerså and colleagues among registered health care providers in Swedish surgical care indicating that majority of the participants had none or minor knowledge of complementary and alternative medicine ${ }^{[13]}$.

From the results (table 4.3) majority of nurses reported they had recommended CAM therapy to their patients $(57.8 \%)$ and in disease conditions like typhoid's, Pain management and incurable diseases. This is in line with findings reported by Astinand colleagues) where CAM was used for pain management, control of chronic diseases and management of an on-going health concern, and also with similar studies by Beebe, where subjects used CAM to help them better manage health related issues, including pain management, chronic disease management, and improving the odds of staying healthy ${ }^{[2,14]}$.

However this study is not in line with studies by Singh where the most common conditions that CAM was used for: diabetes $(22.1 \%)$, headaches $(22.1 \%)$ and arthritis or joint pains $(18.2 \%)^{[12]}$. This study recorded that most nurses recommend CAM for treatment of typhoid, this could be due to the false perception by community members that

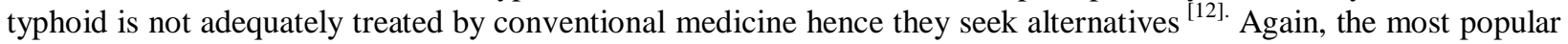


laboratory investigation for typhoid in our setting is a serological test which remains positive for sometimes even after adequate treatment, giving a false impression that treatment was not adequate.

Again, CAM is recommended for most terminal illnesses especially after the attending physician says the condition is terminal. This could be because at this point, most patients are in denial hence would hold on to the slightest hope offer them by the nurses.

Participants were questioned about the frequency with which they encountered patients who enquired about alternative therapies (table 4.4). About (64.4\%)) did encounter patients in nursing practice who frequently enquired about alternative therapies. This result is in line with other studies where alternative therapies were found to be used frequently by the general public ${ }^{[15]}$. On the other hand, is not in line with the $(70 \%)$ reported by Loshni in South Africa stating that patients seldom enquired about alternative therapies ${ }^{[16]}$. The fact that nurses reported that most patients enquired about alternative therapies may be due to the popularity of these therapies in our community; because many persons are aware of their existence, many tend to ask about it also persons suffering from terminal illnesses search for all available alternatives including CAMs. This supports the need for nurses to be prepared to be aware of the different types of CAM, its benefits and risks and integration within nursing care.

Professional nurses views about the inclusion of alternative therapies in nursing practice was also explored (figure 4.1). More than half of the participants $(60 \%)$ were in agreement that CAM should be used in clinical settings. Similar findings were made in a Kuwaiti study with nurses, where about a third of the sample (61.6\%) also agreed that CAM be included in clinical treatment of diseases ${ }^{[17]}$. This could be due to the predicted increase in global burden of chronic diseases ${ }^{[2]}$. This too may be due to nurses witnessing the therapeutic benefits of alternative therapies amongst patients who use them.

However this study is not in line with Loshni where about $70 \%$ of the participants disagreed that alternative therapy was a threat to patient's health ${ }^{[18] .}$ Nearly $60 \%$ of the sample disagreed that alternative therapies were outside of the scope of nursing practice. This may be due to the fact that care of terminal patients in our settings is still in an inchoate stage hence nurses recommend CAM when they should have recommended patients being transferred to a terminal care medical facility.

Findings of this study (figure 4.2) revealed nurses' positive perception about CAM (88.9\%) which is similar to

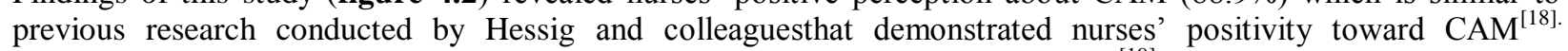
According to Rojas-Cooley, nurses' attitudes towards CAM were positive overall ${ }^{[19]}$. The positive attitudes of this sample towards the use of alternative therapies in nursing practice, implies that nurses do encounter patients who require and are willing to use these therapies ${ }^{[16]}$.

\section{Conclusion:-}

This study found that majority of nurses at the Bamenda Regional Hospital know of CAM with the most common known types being traditional medicine (51.4\%) and spiritual healing $(27.0 \%)$. These nurses frequently enquired patients who used CAM $(82.2 \%)$, recommended CAM modalities to them and treated them like any other patient $(83.3 \%)$. Overall nurses had positive perception about CAM and will accept CAM use in the clinical setting.

\section{Recommendations:-}

The school should encourage students to carry out more research in this area.

To facilitate the infusion of CAM in nursing practice, the ministry of public health should organized workshops and seminars to strengthen nurses' knowledge of traditional medicine and spiritual healing.

The policy makers/ministry of public health should provide grants for research

To provide more evidence based information about CAM more studies needs to be done. Education of the future medical providers, researchers and decision makers should include studies regarding CAM to wake their interest.

For nurses to respond to the challenges that the simultaneous use of CAM and conventional medicine cause, curriculum of the future medical personnel should include studies regarding CAM. 
The results revealed a positive perception of CAM use amongst nurses at the Bamenda Regional Hospital. The study should be replicated in other regions of the country to gain a more comprehensive understanding of nurses' perception. This shows the willingness to incorporate CAM in clinical setting and the government should endeavour to facilitate.

\section{References:-}

1. Theresa Hermandez (2010). Department of Psychology and Neuroscience, University of Colorado at Boulder

2. World Health Organization (2013). WHO Traditional Medicine Strategy 2014-2023. Geneva. WHO Press

3. Eisenberg DM, Davis RB, Ettner SL, Appel S, (1998). Trends in alternative medicine use in the United States. Journal of the American Medical Association.

4. Brodeker G and Kronenberg F, (2002). "A public health agenda for traditional, complementary and alternatives medicines," American Journal of Public Health 92/10, pp. 1582-1591.

5. Ananth, S. (2012). More hospitals offering CAM. Hospitals \& Health Networks. Retrieved from :http://www.hhnmag.com/hhnmag/HHNDaily/HHNDailyDisplay.dhtml?id=18000 7602

6. Ajazuddin and Saraf, S. (2012). Legal regulations of complementary and alternative medicines in different countries. Pharmacognosy Reviews, 6(12): 154.

7. Sackett, K., Carter, M. and Stanton, M. (2014). Elder's Use of Folk Medicine and Complementary and Alternative Therapies: An integrative review with implications for case managers. Professional Case Management. 19(3): 113-123.

8. Mander, M., Ntuli, L., Diederichs, N. and Mavundla, K. (2007). Economics of the traditional medicine trade in South Africa: health care delivery. South African Health Review.189-196.

9. Emmett, D. (2014). Problems with alternative medicines in the health care setting: From nurses' experience. Journal of Business and Economics, 5(7): 945-950.

10. Sawalha, A. F. (2007). Complementary and alternative medicine (CAM) in Palestine: use and safety implications. The Journal of Alternative and Complementary Medicine, 13(2): 263-270

11. Johnson, S. E., Green, J. and Maben, J. (2013). A suitable job? A qualitative study of becoming a nurse in the context of a globalising profession in India. International Journal of Nursing Studies: 1-26. Available online http://researchonline.lshtm.ac.uk/1277151/

12. Singh, V., Raidoo, M. D. and Harries, C. S. (2004). The prevalence, patterns of usage and people's attitude towards complementary and alternative medicine (CAM) among the Indian community in Chatsworth, South Africa. BMC Complementary and Alternative Medicine 4(3): 1472-6882.

13. Bjerså, K., Stener, V.E. \&Fagevik, O.M. (2012). Knowledge about complementary, alternative and integrative medicine (CAM) among registered health care providers in Swedish surgical care: a national survey among university hospitals. Referred 8.4.2014

14. Hoving, J.L., de Vet, H.C., Koes, B.W., Hameren, H., Devillé, W.L., van der Windt, D.A., Assendelft, W.J., Pool, J.J., Scholten, R.J., Korthals-deBos, I.B. \&Bouter, L.M. (2006). Manual therapy, physical therapy, or continued care by the general practitioner for patients with neck pain: long-term results from a pragmatic randomized clinical trial. The Clinical Journal of Pain. 224): 370-377. Referred 5.5.2014. Http://www.jamk.fi/kirjasto, Nelli-portal,

15. Chu, F-Y.and Wallis, M. (2006). Taiwanese nurses' attitudes towards and use of complementary and alternative medicine in nursing practice: A cross sectional survey. International Journal of Nursing Studies, 44(2007): 1371-1378.

16. Mander, M., Ntuli, L., Diederichs, N. and Mavundla, K. (2007). Economics of the traditional medicine trade in South Africa: health care delivery. South African Health Review.189-196.

17. Awad, A. I., Al-Ajmi, S. and Wheedi, M. A. (2012). Knowledge, perceptions and attitudes toward complementary and alternative therapies among Kuwaiti medical and pharmacy students.Medical Principles and Practice, 21(4): 350-354.

18. Hessig, R. E., Arcand, L. L., \& Frost, M. H. (2004). The effects of an educational intervention on oncology nurses' attitude, perceived knowledge, and self-reported application of complementary therapies. Oncology Nursing Forum, 31(1), 71-78

19. Rojas-Cooley, M., \& Grant, M. (2009). Complementary and alternative medicine: Oncology nurses' knowledge and attitudes. Oncology Nursing Forum, 36(2), 217-224. doi:10.1188/09.ONF.217-224. 